\title{
Flexible use of simple and combined calls in female Campbell's monkeys
}

\author{
Camille Coye $^{1,2,3}$, Karim Ouattara ${ }^{3,4}$, Malgorzata E. Arlet ${ }^{1,5,6}$, Alban Lemasson ${ }^{1}$, Klaus \\ Zuberbühler ${ }^{2,37}$
}

${ }^{1}$ Université de Rennes 1, Ethologie animale et humaine - EthoS, U.M.R 6552-C.N.R.S, Station Biologique, 35380 Paimpont, France; ${ }^{2}$ University of St Andrews, School of Psychology and Neuroscience, St Andrews, Fife KY16 9AJ, UK; ${ }^{3}$ Centre Suisse de Recherches Scientifiques, Taï Monkey Project, Adiopodoumé, Abidjan Ivory Coast; ${ }^{4}$ Laboratoire de Zoologie et Biologie animale, Université Félix Houphouët-Boigny - Abidjan, Côte d'Ivoire, 22 BP 582 Abidjan 22; ${ }^{5}$ Indian Institute of Science Education and Research Thiruvananthapuram, Centre for Research and Education in Ecology and Evolution, Thiruvananthapuram, India; ${ }^{6}$ Adam Mickiewicz University in Poznan, Institute of Anthropology, Poznań, Poland; ${ }^{7}$ Université de Neuchâtel, Institut de Biologie, rue Emile Argand 11, 2000 Neuchâtel, Switzerland.

Corresponding author: camillecoye@gmail.com

Correspondence address: Centre for Ecology and Conservation, University of Exeter, Penryn Campus, Penryn, Cornwall, TR10 9FE, UK

Call combinations allow animals to expand the communicative power of small repertoires with acoustically inflexible elements. In Campbell's monkeys, males possess a small repertoire of calls that can be merged to an acoustically invariable affix and which are concatenated into various sequences, mainly in response to external disturbances. The vocal repertoire of adult females has been less well studied although it is much richer, containing both alarm and various social calls. In particular, females possess a low-pitched contact call, produced either alone or merged with a high-pitched, arched unit. Combined contact calls are identity-richer and easier to detect than simple calls. Here, we investigated the socio-ecological factors that determined the production of single and combined utterances and found that combined utterances were more common when identity was relevant such as in mixed species association and during socially important vocal exchanges. On the contrary, single calls were used mainly when predation risk was high, as part of this species' generally cryptic antipredator strategy. We discuss these finding in light of current theories regarding the evolution of combinatorial signalling.

Key-words: call combination, contact calls, evolution of communication, referential signalling, vocal flexibility, vocal signature 
Living in groups provides anti-predation benefits but also requires coordination and communication between group members (Gautier \& Gautier, 1977; Lehmann, Korstjens, \& Dunbar, 2007; Oda, 1996; Uster \& Zuberbühler, 2001; see Bennett \& Cuthill, 1994; Osorio \& Vorobyev, 2008; Wyatt, 2003 and Liebal, Waller, Slocombe, \& Burrows, 2013 for reviews). As a result, interactions with predators and conspecifics are likely to act as two major forces in the evolution of animal communication (McComb \& Semple, 2005; Pollard \& Blumstein, 2012; Stephan \& Zuberbühler, 2008). First, predation is the likely driver for alarm call evolution (Hauser, 1996), especially to encode different levels of urgency or predator types (Furrer \& Manser, 2009; Manser, 2001; Pereira \& Macedonia, 1991). Second, the daily challenge of social coordination is the likely driver for social call evolution, with callers generally benefiting from advertising their on-going activity, identity and location to other group-members (Bouchet, Blois-Heulin, \& Lemasson, 2013; Manser et al., 2014).

As a general pattern, increasing social complexity, e.g. via group size or diversification of social roles, is thought to select for more complexity in communication, e.g. via larger repertoire size or more informative signals (Freeberg, Dunbar, \& Ord, 2012; Manser et al., 2014; McComb \& Semple, 2005). This is mainly because individuals are faced by more complex coordination problems resulting from increasingly complex social networks (Freeberg et al., 2012; McComb \& Semple, 2005; Seyfarth, Cheney, \& Bergman, 2005). However, most mammals and particularly non-human primates are constrained in how much motor control they have over their vocal tracts (Lameira, Maddieson, \& Zuberbühler, 2014). As a result, vocal repertoires tend to be small with only limited numbers of call types (Hammerschmidt \& Fischer, 2008). Enlarging the repertoire by generating new acoustic structures, in other words, may simply not be possible for most species.

One way to enhance the communicative power of such limited systems is to evolve the ability to produce acoustic variants within the main vocal classes, a persistent finding in many species (Bouchet et al., 2013; Gustison, Roux, \& Bergman, 2012; Knotkova, Veitl, Sumbera, Sedlacek, \& Burda, 2009; Le Roux, Cherry, \& Manser, 2009). Another way to is merge existing vocal units into combined calls consisting of different acoustic elements uttered in close succession (Bouchet, Pellier, Blois-Heulin, \& Lemasson, 2010a; Coye, Zuberbühler, \& Lemasson, 2016; Lemasson \& Hausberger, 2011). A third way to overcome limited vocal control is to combine calls with existing meaning into longer sequences, with sometimes modified meanings (Arnold \& Zuberbühler, 2008; Engesser, Ridley, \& Townsend, 2016; Lemasson, 2011; Schlenker et al., 2016; Zuberbühler \& Lemasson, 2014) In this case, the relevant vocal units are single calls 
separated by inter-call intervals (Berwick, Okanoya, Beckers, \& Bolhuis, 2011; Bohn, SchmidtFrench, Ma, \& Pollak, 2008; ten Cate \& Okanoya, 2012). The latter two mechanisms are of particular interest because of possible similarities with human phonology and syntax (Collier, Bickel, Schaik, Manser, \& Townsend, 2014). Whether or not they result from the same phenomenon, or should be considered distinct processes, is currently unknown and requires further research.

There has been considerable recent surge in studies with evidence for combinatorial structures in birds (Engesser, Crane, Savage, Russell, \& Townsend, 2015; Engesser, Ridley, \& Townsend, 2016; Suzuki, Wheatcroft, \& Griesser, 2016), but also terrestrial mammals (Jansen, Cant, \& Manser, 2012; Kershenbaum, Ilany, Blaustein, \& Geffen, 2012) and primates (Cäsar, Byrne, Young, \& Zuberbühler, 2012; Clarke, Reichard, \& Zuberbühler, 2006; Clay \& Zuberbühler, 2011; Crockford \& Boesch, 2005; Hedwig, Mundry, Robbins, \& Boesch, 2015). Amongst the latter, combinatorial systems have been identified in male alarm calls of Campbell's monkeys, Cercopithecus campbelli (Coye, Ouattara, Zuberbühler, \& Lemasson, 2015; Ouattara, Lemasson, \& Zuberbühler, 2009a, 2009b; Zuberbühler, 2002); putty-nosed monkeys, C. nictitans (Arnold \& Zuberbühler, 2008, 2012), and in female social calls of Diana monkeys, $C$. diana (Candiotti, Zuberbühler, \& Lemasson, 2012a; Coye et al., 2016). Although it is evident that callers can increase the number of acoustic structures by producing combinations of limited sets, the communicative function of such combinations is not so self-evident, especially for social calls.

Animals living in societies with individualised relationships, as is the case for primates, need to recognise each other individually (Arlet, Jubin, Masataka, \& Lemasson, 2015; Candiotti, Zuberbühler, \& Lemasson, 2013; Kondo \& Watanabe, 2009; Rendall, Rodman, \& Emond, 1996), especially if they live in visually dense habitats (Candiotti et al., 2013; Lemasson \& Hausberger, 2011). Unsurprisingly, individually distinctive calls have been described in many group-living animals (Jansen et al., 2012; Kondo \& Watanabe, 2009; Le Roux et al., 2009; Palombit, Seyfarth, \& Cheney, 1997) but not all call types seem to be affected in the same way (Bouchet, Blois-Heulin, Pellier, Zuberbühler, \& Lemasson, 2012; Lemasson \& Hausberger, 2011). As a general pattern, social calls tend to contain higher degrees of individual signatures than alarm calls (Bouchet et al., 2013; Bouchet et al., 2012; Lemasson \& Hausberger, 2011). Furthermore, there is also evidence that, within di

fferent social calls, identity is encoded flexibly and to various degrees, depending on context or audience composition (e.g., starlings, Sturnus vulgaris Adret-Hausberger, 1982, 1989; Henry \& 
Hausberger, 2001; zebra finch, Taeniopygia guttata Vignal, Mathevon, \& Mottin, 2004; Gray mouse lemur, Microcebus murinus Leliveld, Scheumann, \& Zimmermann, 2011; Diana monkeys Candiotti, Zuberbühler, \& Lemasson, 2012b).

Here, we focus on Campbell's monkeys, a species for which combinatorial capacities have been described before in male calls (Coye et al., 2015; Ouattara, Lemasson, \& Zuberbühler, 2009b; Ouattara, Lemasson, et al., 2009a). Campbell's monkeys are territorial, arboreal guenons living in West African tropical forests, often in association with other primate species (McGraw, Zuberbühler, \& Noë, 2007). They form harem groups with one single adult male and several adult females with their offspring (Candiotti et al., 2015). The adult male does not interact much with other group members and, probably as a result, his vocal repertoire is limited to a few acoustically stereotyped alarm calls, given in different sequence compositions according to external events (Coye et al., 2015; Lemasson, Ouattara, Bouchet, \& Zuberbühler, 2010; Ouattara, Lemasson, et al., 2009a). Three basic alarm calls have been distinguished (Keenan, Lemasson, \& Zuberbühler, 2013), which can be further modified by an acoustic affixation principle (Ouattara, Lemasson, et al., 2009a) to express differences in perceived urgency. Affixation is meaningful for listeners, as recently demonstrated experimentally with wild Diana monkeys from a sympatric population to Campbell's monkeys (Coye et al 2015). In Campbell's monkeys, the adult females constitute the social core of the group and form stable social bonds of variable strength with each other (Candiotti et al., 2015; Lemasson, Gandon, \& Hausberger, 2010; Lemasson \& Hausberger, 2004). They produce a range of alarm and social calls, to navigate in a visually restricted habitat (Brown, Gomez, \& Waser, 1995; Marler, 1965; Waser \& Brown, 1986). The most common calls are contact calls, which appear in three types (Lemasson \& Hausberger, 2011): SH (short harmonic), CHb (combined harmonic broken) and CHf (combined harmonic full). SH types are low-pitched and can be uttered alone or combined with an arched frequency modulation to form broken or full $\mathrm{CH}$ types (i.e. which involve respectively a partial or complete arched-shaped frequency modulation merged after the 'SH" part, Fig. 1).

The combinatorial structure of Campbell's monkeys contact call system needs to be verified experimentally (e.g. by testing the relevance of recombined calls to receivers). Yet, its marked resemblance with the call system of Diana monkeys strongly suggests that both rely on a similar combinatorial mechanism. Female Diana monkeys possess calls very similar to the calls of Campbell's monkeys (e.g. with calls structurally homologous to RRA, SH, CHb and CHf calls, Candiotti et al., 2012; Lemasson \& Hausberger, 2011). Contrarily to Campbell's monkeys however, Diana monkeys can form combined calls by merging an arched unit to distinct calls 
relating to the emotional context (e.g. to RRA-like calls in negative contexts or to SH-like calls in neutral context). Observational and playback studies on wild Diana monkeys demonstrated that combined calls are meaningful to receivers and that their meaning depends on the vocal units involved (Coye et al., 2016b).

While the context of emission and likely function of call combination has been elucidated in Diana monkeys, they remain unclear in Campbell's monkeys. In particular, the possible advantage of this very limited system (i.e. which only allows the combination of arches to SH calls) and its possible functions (i.e. why would females use three distinct calls for the same apparent purpose?) are obscure. One possible path to explain this pattern lies in calls' potential for identity coding which varies with the presence and completeness of an arched unit (Lemasson \& Hausberger, 2011). This is so because the Potential for Identity Coding of Campbell's monkeys' contact calls gradually increases between low-pitched (SH), broken harmonic combinations $(\mathrm{CHb})$ and full harmonic combinations (CHf), with the latter encoding identity most strongly (Lemasson \& Hausberger, 2011).

Here we hypothesize that female social communication in Campbell's monkeys may rely on the flexible use of contact calls that differ in the presence and 'completeness' of an arched unit (i.e. broken or complete) as a function of the contextual need to signal identity. To test this hypothesis and gain insights into the function of combined calls in this guenon, we analysed spontaneous call production of wild female Campbell's monkeys. Specifically, we focussed on how females used the different social call types depending on context. We predicted that the identity-rich combined harmonic units (CHf) are used preferentially when responding to a closely bonded female or when individual recognition is important or visually difficult, such as when (a) in large poly-specific associations (which tend to be noisy), (b) intergroup encounters are likely (periphery of the territory), or (c) visibility is low (dense vegetation, low forest stratum).

\section{MATERIAL AND METHODS}

\section{Study site and subjects}

Data were collected between August 2006 and February 2007 from two groups of free-ranging Campbell's monkeys in Taï National Park, Ivory Coast $\left(5^{\circ} 50^{\prime} \mathrm{N}, 7^{\circ} 21^{\prime} \mathrm{W}\right)$. Both groups were fully habituated to human presence, and their home ranges were known (Ouattara, Lemasson, et al., 2009a). Groups included one adult male each and 7 and 3 individually known adult females 
with their offspring, respectively. Campbell's monkeys spend most of their time in association with other species of primates, notably Diana monkeys, but also lesser spot-nosed monkeys (Cercopithecus petaurista), sooty mangabeys (Cercocebus atys), olive colobus (Procolobus verus), king colobus (Colobus polykomos), and red colobus (Colobus badius) (Buzzard \& Eckardt, 2007; Mcgraw \& Zuberbühler, 2008).

\section{Ethical note}

This study is based on observational data collected on habituated groups of wild Campbell's monkeys that have been followed regularly for more than a decade. Observer presence has no noticeable negative effects on the daily life and welfare of habituated primate subjects and such studies, in most people's views, do not raise any ethical concerns. The study has been approved by the Ivorian Ministry of Scientific Research, the relevant government authority for ethical assessments, and the Ivorian Office of Parks and Reserves to access to the Tai National Park.

\section{Data collection}

One observer (KO) followed each group from 7:30am to 5:00pm on alternate days. Every 15 minutes, an adult female was selected randomly and her behaviour was scored as foraging, locomotion, social interactions or observing the environment. Vocalisations and strata use were also recorded (see Table A1 for definitions). Scan samples were taken every 30 min to score the position of the group in the territory, the number and identity of associated species and, for each visible adult, her distance to and identity of the closest group member (Table A1). Vocalisations were recorded with a Sony TCD D100 DAT recorder, a Sennheiser ME88 directional microphone (for monkey calls) and a Lavallier microphone (for spoken comments). A total of 54 hours of observations and recordings were collected, from ten adult females (mean \pm ES: $5.40 \mathrm{~h} \pm 0.43$ per individual).

\section{Call classification}

Calls were classified by audio-visual inspection using the ANA software (Richard, 1991). MA labelled the call type (following Lemasson \& Hausberger 2011's classification) of each vocalisation emitted by the focal subject and noted whether the call was or was not part of a call exchange. Four acoustic categories were defined: RRA (Repetitive Rapid Ascending) Alarm calls, and three types of contact calls: SH calls (Short Harmonic), CHb calls (Combined Harmonic 'Broken' arch), CHf calls (Combined Harmonic 'Full' arch; Fig. 1). All N= 506 calls (RRA: $N=49, \mathrm{SH}: N=46, \mathrm{CHb}: N=324$, CHf: $N=68$, calls discarded because of low quality or 
uncertain caller identification: $N=19$ ) were recoded and displayed using Raven Pro 1.4 software to confirm classification. Agreement between CC and MA was 93.2\%. Disputed cases were arbitrated by AL. A vocal exchange was defined as a sequence of vocalisations emitted by several individuals, each separated by less than one second (Lemasson, Gandon, et al., 2010).
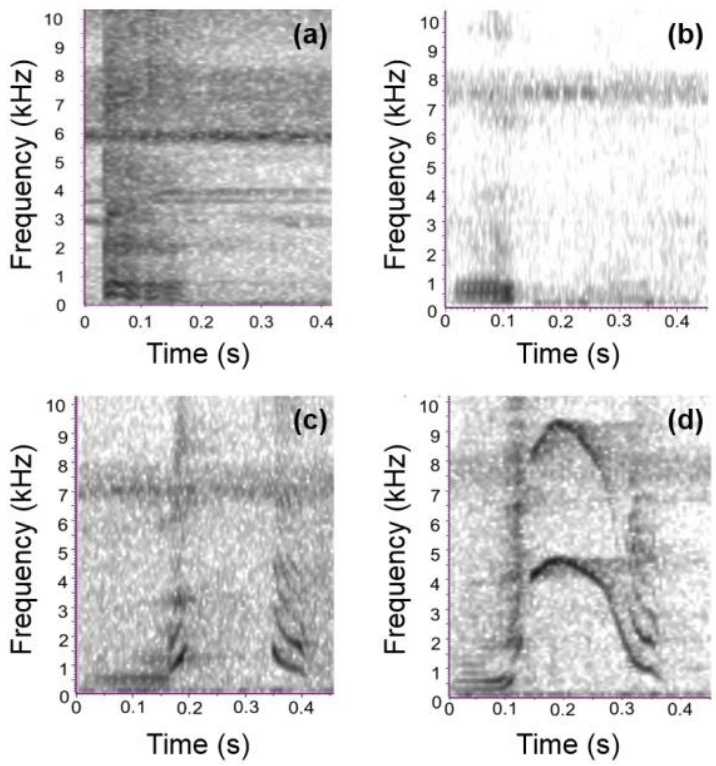

Figure 1: Spectrographic representation of female Campbell's monkeys' vocal units: (a) RRA: Rapid repetitive ascending alarm calls, (b) $\mathrm{SH}$ : Short harmonic (low-pitched contact call), (c) CHb: Combined harmonic broken (i.e. $\mathrm{SH}$ merged with a broken arch), and (d) CHf: Combined harmonic full (i.e. SH merged with a full arch). See Lemasson \& Hausberger 2011 for acoustic definitions.

\section{Variables and analyses}

We analysed the influence of various socio-ecological factors on adult females' vocal behaviour (see Table A1 for definitions). (Smith, 1965) highlighted that both the immediate and the 'historical' context (i.e. individual's past experiences, influencing subject's social relations and reactions) may be important in determining the meaning and function of a call. Guenons use contact calls to maintain spatial proximity to others, especially to preferred partners. Hence, we analysed call production in relation to long-term measures of a female's socio-spatial integration and in relation to the immediate context of calling. Detailed definitions for each variable measured are available in Table A1 of Appendix. We used two-tailed statistical tests with a 0.05 significance threshold.

\section{Socio-spatial integration}

To evaluate the relation between calling behaviour and social integration, we calculated, for each female, the relative time (i.e. per hour of observation) of grooming given to and received from other adult group members. Each individual's grooming score (i.e. time spent grooming divided by time of observation) was then correlated with her call rate (i.e. number of calls given by the focal female divided by time of observation) for each call type, using Spearman rank 
tests. To assess subjects' spatial integration, we also calculated the average distance to the closest neighbour (mean distance calculated using half-hour scan sampling) for each female. We then correlated each female's spatial score with her different call rates using Spearman rank tests.

\section{Immediate context}

We analysed several socio-ecological variables susceptible to influence call use at the time of calling (see Table 1 for a summary of statistical analyses conducted). We used two complementary measures to quantify females' behaviour:

(1) To control for differences in sampling efforts, we calculated the individual call rates for all 10 females (i.e. the number of calls of a given type given by individual $\mathrm{X}$, divided by the observation time of individual $\mathrm{X}$ ).

(2) To account for females' repertoire use, we calculated the proportions of each call type for each female. For this, we calculated, for each individual separately, the proportion of calls given that each call type represented. Finally, as vocal exchanges play an important social role in Campbell's monkeys, we analysed for each call type the proportion of calls given in isolation and exchanged (see Table A1 for definitions).

Data were analysed with non-parametric statistical tests. We used non-parametric rank sum tests to assess changes in call rates for each contextual variable. Although not very powerful, these test are conservative and adequate for our small dataset. In addition, we used binomial GLMMs to account for repertoire use as this procedure was better suited for analyses of proportions while controlling for subject identity and group membership.

\section{$\underline{\text { Call rates }}$}

To assess whether subjects changed their calling behaviour as a function of the immediate ecological context, we compared call rates as a function of (a) the number of associated species, (b) position in the territory, (c) strata use. Depending on the ecological variable, we used either Wilcoxon rank sum tests (for variables with two levels) or Friedman ANOVA (for variables with more than two levels, see Table 1). If significant, we performed pairwise Wilcoxon tests with False Discovery Rate (FDR) correction and continuity corrections if necessary. We performed this analysis for two of the three aforementioned variables (i.e. number of associated species and proximity to the territory periphery) because an unbalanced observational design 
prevented the use of a Friedman test on subject's strata (most subjects were observed in only three of the four strata). Hence instead, to assess a link between call rate and caller's strata, we calculated a Spearman correlation between subject's strata when calling and call rate, for each call type separately.

To determine whether calling behaviour was influenced by ongoing behaviour (locomotion, feeding, observing the environment; see Table 1), we compared rates of each call type across contexts using Friedman ANOVA followed by pairwise Wilcoxon tests with FDR correction.

\section{Repertoire use}

Similar to call rate analysis, we studied repertoire use by females a function of (i) the number of associated species, (ii) proximity to the territory periphery and (iii) strata use. For each call type, we determined its proportional use in different contexts using binomial Generalized Linear Mixed Models (GLMM, link: logit). For instance, we compared the proportion of SH calls when the density of associated primates was high or low. The proportion of RRA calls given in each context was calculated over the total number of all calls given in the same context (i.e. RRA + contact calls). For a more fine-tuned analysis however, the proportion of each contact call type ( $\mathrm{SH}, \mathrm{CHb}$ and $\mathrm{CHf}$ ) was calculated over the number of contact calls given (i.e. $\mathrm{SH}+\mathrm{CHb}+\mathrm{CHf}$ calls only). The model included systematically the contextual factor as the only fixed factor and subject's identity and group as random factors (glmer() function, \{lme4\} R package). We computed post-hoc tests when necessary using least-squares means analysis (lsmeans() function, \{lsmeans $\}$ R package).

We analysed the proportion of each call type across the three behavioural contexts (i.e. locomotion, feeding, observing the environment) using binomial Generalized Linear Mixed Models (GLMM, link: logit). Proportions of alarm calls and of each contact call type were calculated over the total number of calls given, and over the total number contact calls given respectively. The model included the behaviour preceding calling as a fixed factor and subject's identity and group as random factors (glmer() function, $\{$ lme4 $\}$ R package). We computed posthoc tests when necessary using the least-squares means analysis (lsmeans() function \{lsmeans $\mathrm{R}$ package).

\section{Vocal exchanges}

To determine whether calling behaviour was influenced by vocal exchanges, we compared call rates emitted in isolation (i.e. given more than 1s away from a conspecific's call) and during 
vocal exchanges for each call type using Wilcoxon tests with continuity correction. In addition, to determine whether some call types were used preferentially in a given vocal context (i.e. either exchanged or in isolation), we compared the proportion of isolated and exchanged calls for each call type. We used a binomial GLMM (link: logit), with the vocal context (i.e. call given in isolation or during an exchange) as a fixed factor and caller's identity as a random factor (glmer() function, \{lme4\} R package). This latter proportion analysis thus differs from the one applied to other ecological and behavioural variables (i.e. the proportions of isolated vs exchanged calls were calculated within each call type) as it was more relevant in this case.

Table 1: Summary of statistical analyses:

\begin{tabular}{|c|c|c|c|}
\hline $\begin{array}{l}\text { Type of context } \\
\text { analysed }\end{array}$ & $\begin{array}{l}\text { Biological relevance } \\
\text { of the factor }\end{array}$ & Variable & Statistical analyses \\
\hline \multirow{2}{*}{$\begin{array}{l}\text { Long-term } \\
\text { socio-spatial } \\
\text { integration in } \\
\text { the group }\end{array}$} & Social & $\begin{array}{l}\text { Time spent grooming } \\
\text { with others }\end{array}$ & Spearman correlation (call rate) \\
\hline & \multirow[t]{2}{*}{ Spatial } & $\begin{array}{c}\text { Distance to the closest } \\
\text { neighbour }\end{array}$ & Spearman correlation (call rate) \\
\hline \multirow{5}{*}{$\begin{array}{l}\text { Immediate } \\
\text { context of } \\
\text { calling }\end{array}$} & & $\begin{array}{l}\text { Number of associated } \\
\text { primate species }\end{array}$ & $\begin{array}{c}\text { Wilcoxon test (call rate) } \\
+ \text { binomial GLMM (repertoire use) }\end{array}$ \\
\hline & \multirow[t]{2}{*}{ Ecological } & Position in the territory & $\begin{array}{c}\text { Wilcoxon test (call rate) } \\
+ \text { binomial GLMM (repertoire use) }\end{array}$ \\
\hline & & Stratum used & $\begin{array}{l}\text { Spearman correlation (call rate) } \\
+ \text { binomial GLMM (repertoire use) }\end{array}$ \\
\hline & \multirow{2}{*}{ Social } & $\begin{array}{l}\text { Behaviour before } \\
\text { calling }\end{array}$ & $\begin{array}{c}\text { Friedman ANOVA (call rate) } \\
+ \text { binomial GLMM (repertoire use) }\end{array}$ \\
\hline & & $\begin{array}{l}\text { Call isolated or } \\
\text { exchanged }\end{array}$ & $\begin{array}{c}\text { Wilcoxon test (call rate) } \\
+ \text { binomial GLMM (repertoire use) }\end{array}$ \\
\hline
\end{tabular}

\section{RESULTS}

Overall, we found similar call rates across RRA alarm calls, SH calls and CHf calls (RRA: 0.015/min (0.90/h), SH: 0.016/min (0.96/h), CHf: 0.02/min (1.2/h). CHb calls, however, were much more common and given at $0.100 / \mathrm{min} .6 .00 / \mathrm{h}$ ). A table giving a summary overview of the results described below is provided at the end of the result section (Table 2).

\section{Socio-spatial integration}

Females' social relations were not correlated with preferential use of any call type. In particular, there were no significant correlations between call rates of any call type and the time each subject spent grooming with the adult male or other adult females (Spearman correlation tests: 
$N=10, \mathrm{Df}=8$, FDR correction for multiple correlations; Adult male: RRA calls: $S=249.60, P=$ 0.52 , rho= -0.51 ; SH: $S=162.94, P=0.97$, rho= 0.01; CHb: $S=217.62, P=0.74$, rho= $=0.32$;

CHf: $S=142.30, P=0.94$, rho=0.14; Adult females: RRA calls: $S=186, P=0.73$, rho= $=0.13$; SH: $S=98, P=0.73$, rho= 0.41; CHb: $S=136, P=0.73$, rho=0.18; CHf: $S=114, P=0.73$, rho= $0.31)$.

Similarly, the female spatial integration was not correlated with preferential use of any call type. There were no significant correlations between the average distance to the closest neighbour and the different call rates (Spearman correlation, p-values adjusted for multiple comparison using FDR method: $N=10, \mathrm{Df}=8$, RRA calls: $S=266, P=0.27$, rho= $-0.61 ; \mathrm{SH}: S=144, P=0.89$, rho= 0.13; CHb: $S=174, P=0.89$, rho= -0.06; CHf: $S=98, P=0.50$, rho=0.41).

\section{Immediate context}

\section{Associated primate species}

The number of associated primates (low vs. high, Tables $1 \& 2$ ) influenced the subjects' calling behaviour. RRA and CHf call rates were significantly higher when the density of associated species was high than when it was low, but no significant effects were found for $\mathrm{SH}$ and $\mathrm{CHb}$ calls (Wilcoxon rank sum test, $N=10$ individuals, RRA calls: $\mathrm{W}=10, P=0.0006$; $\mathrm{SH}$ calls: $\mathrm{W}=$ $50, P=0.37$; $\mathrm{CHb}$ calls: $\mathrm{W}=32.5, P=0.50$; CHf calls: $\mathrm{W}=18, P=0.04)$.

SH calls represented a significantly higher proportion of contact calls given when the density of associated species was low compared to high (Fig. 2, Binomial GLMM, Df= 3, SH calls: Chisq= 9.08, $P=0.0025$ ), but no significant effect was found for the other three call types (Fig. 2, Binomial GLMM, Df= 3, RRA calls: Chisq=0.0002, $P=0.99 ; \mathrm{CHb}$ calls: Chisq=0.3758, $P=$ 0.54; CHf calls: Chisq= 2.90, $P=0.0914)$.

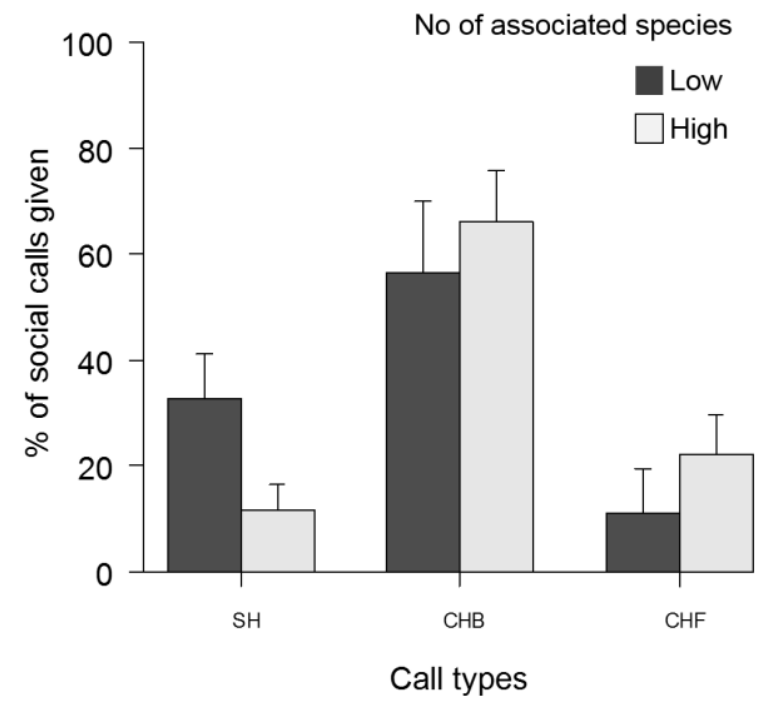

Figure 2: Mean proportion of total social calls given represented by $\mathrm{SH}, \mathrm{CHb}$ and $\mathrm{CHf}$ calls when the density of associated species was low (dark bars) or high (grey bars). Error bars show the standard error of the mean. Note that the values of the bars of a same colour represent the proportion of each contact call type in the same context on the plot and thus add up to $100 \%$. See Table 1 and Methods (Variables and analyses section) for details. 


\section{Position in the territory}

The group's position within their territory did not affect the call rates (centre vs. periphery, Tables $1 \& 2$ : Wilcoxon rank sum test, $N=10$ individuals, RRA calls: $\mathrm{V}=28, P=0.18$; $\mathrm{SH}$ calls: $\mathrm{V}=37, P=0.38$; CHb calls: $\mathrm{V}=24, P=0.91$; $\mathrm{CHf}$ calls: $\mathrm{V}=14, P=0.34)$.

However, CHf calls were given at significantly higher proportions at the periphery than in the centre of the territory (Fig. 3) but this was not the case for the other call types (Table 2, Fig. 3, Binomial GLMM, $N=10, \mathrm{Df}=1$, RRA calls: $\mathrm{Chi}^{2}=1.57, P=0.21$; $\mathrm{SH}$ calls: Chisq=0.0153, $P=$ 0.90; CHb calls: Chisq= 2.59, $P=0.11$; CHf calls: Chisq $=4.05, P=0.044$ ).

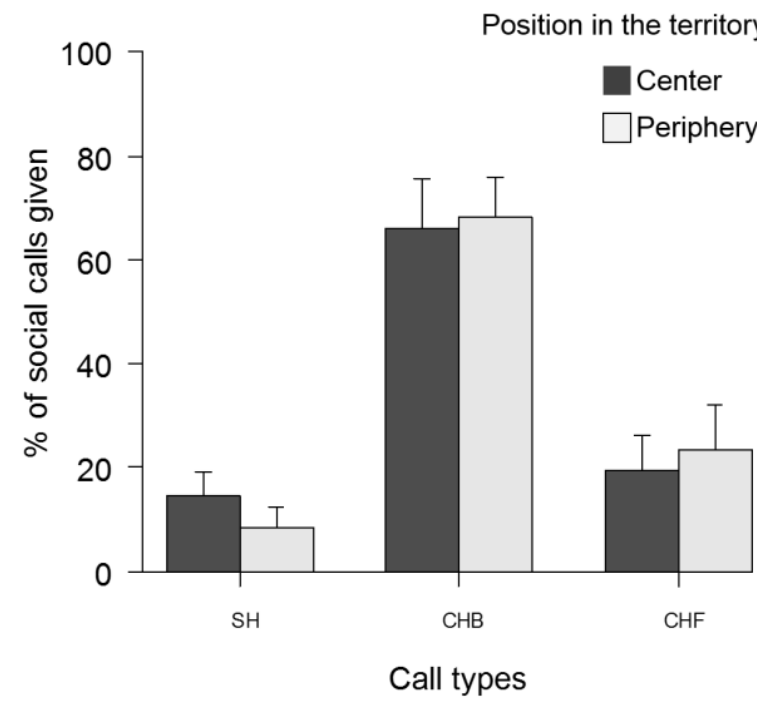

Figure 3: Mean proportion of total social calls given represented by $\mathrm{SH}, \mathrm{CHb}$ and $\mathrm{CHf}$ calls in the centre of the group's territory (dark bars) or at the periphery (grey bars). Error bars show the standard error of the mean. See Table 1 and Methods (Variables and analyses section) for details.

\section{Stratum use}

Strata use influenced call use with correlations with both call rates and proportions (Fig. 4). RRA and CHf call rates were negatively correlated with subject's strata at the time of calling (Spearman correlation, $N=10$ individuals, p-values adjusted for multiple comparisons using FDR correction: RRA calls: $S=7670.23, P=0.0052$, rho= -0.55 ; CHf calls: $S=7547.13, P=$ 0.0052 , rho $=-0.52$ ). More precisely, subjects emitted RRA and CHf calls at significantly higher rates when in low (mostly ground) than high strata, but no such effects were found for SH and $\mathrm{CHb}$ calls (Spearman correlation, $N=10$ individuals, $\mathrm{SH}$ calls: $S=6493.14, P=0.12$, rho= 0.31 ; CHb calls: $S=5342.45, P=0.68$, rho $=-0.08)$.

GLMM analysis of call proportions revealed significant differences between strata for CHf and $\mathrm{CHb}$ calls but not SH and RRA calls (Fig. 4, Binomial GLMM, Df=3, RRA calls: Chisq=0.64, $P=0.89$; SH calls: Chisq= 1.46, $\mathrm{Df}=3, P=0.69 ; \mathrm{CHb}$ calls: Chisq $=9.18, P=0.027$; $\mathrm{CHf}$ calls: Chisq $=10.75, P=0.013)$. Posthoc pairwise comparisons showed that $\mathrm{CHf}$ calls corresponded to a significantly higher proportion of contact calls when subjects were in strata 0 (i.e. on the 
ground) than in strata 1 (Least square means with p-values adjusted for multiple comparisons using Tukey method: S0-S1: $\mathrm{z}=3.11, P=0.01 ; \mathrm{S} 0-\mathrm{S} 2: \mathrm{z}=2.38, P=0.08 ; \mathrm{S} 0-\mathrm{S} 3: \mathrm{z}=2.35, P=$ 0.09 ; the other comparisons: $-1.9<\mathrm{z}<1$ and p-values $>0.2$ ). Interestingly, the proportion of $\mathrm{CHb}$ calls, on the contrary, was significantly higher in strata 1 and 3 than in strata 0 (Least square mean with p-values adjusted for multiple comparisons using Tukey method: S0-S1: $\mathrm{z}=-2.82$, $P=0.025 ; \mathrm{S} 0-\mathrm{S} 2: \mathrm{z}=-2.44, P=0.07 ; \mathrm{S} 0-\mathrm{S} 3: \mathrm{z}=-2.71, P=0.035 ;$ the other comparisons: $-1.2<\mathrm{z}$ $<1.2$ and $\mathrm{p}$-values $>0.6$ ).

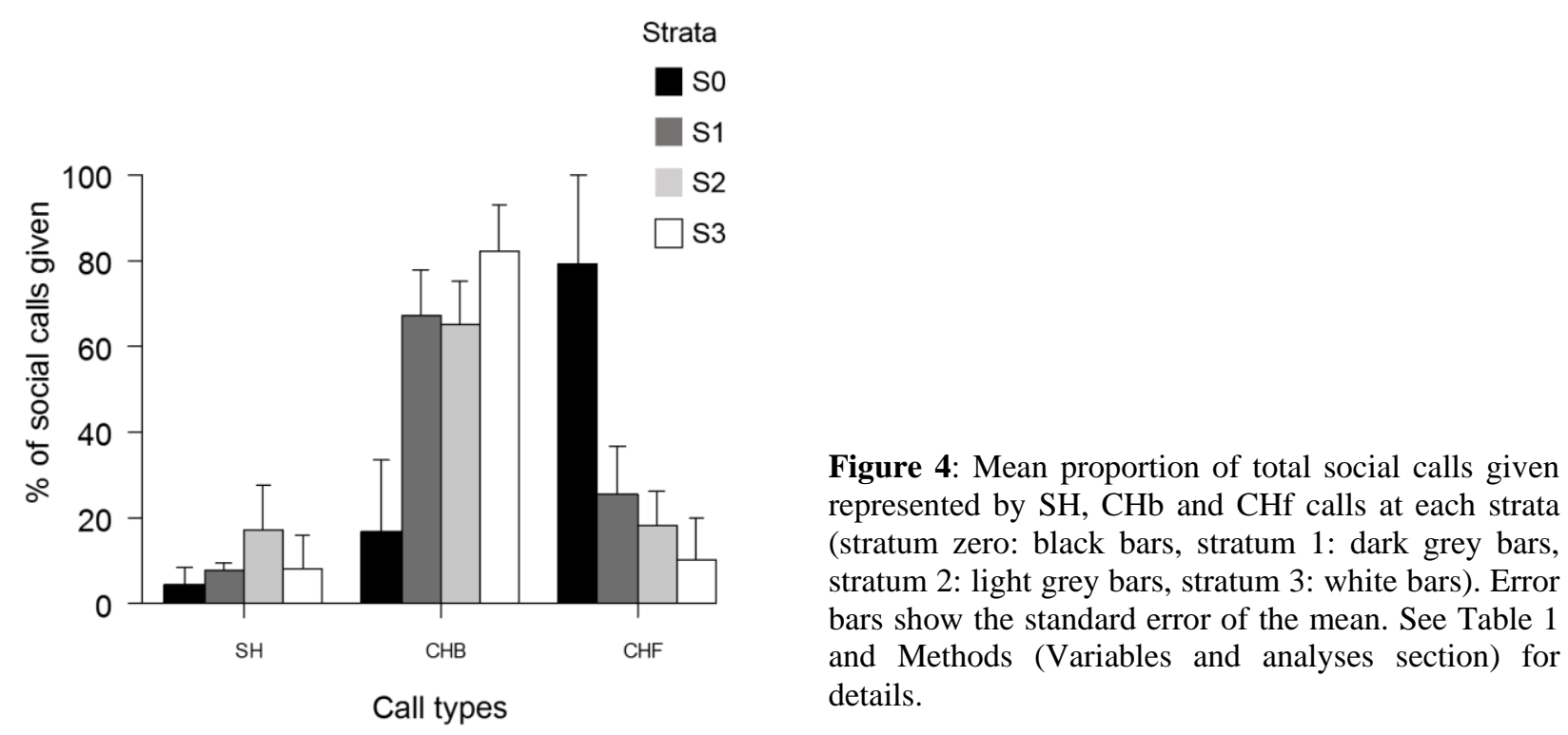

\section{Behavioural context}

Call rates differed significantly depending on the behavioural context (i.e. foraging, locomotion and observation) for every call type tested (Friedman Anova, $N=10, \mathrm{Df}=2$, RRA calls: Chisq= 9.07, $P=0.01$; $\mathrm{SH}$ calls: Chisq $=15.74, P=0.00038 ; \mathrm{CHb}$ calls: Chisq $=14.82, P=0.0006$; $\mathrm{CHf}$ calls: Chisq $=9.21, P=0.01)$. Post-hoc tests showed that call rates during observation were significantly higher than during locomotion or foraging for every call type (Pairwise Wilcoxon tests with false discovery rate correction, $N=10$ individuals, Comparison Observation vs. Locomotion: RRA: $P=0.034, \mathrm{SH}: P=0.014, \mathrm{CHb}: P=0.014$, CHf: $P=0.034$; Observation vs. Foraging: RRA: $P=0.034, \mathrm{SH}: P=0.014, \mathrm{CHb}: P=0.014$, CHf: $P=0.034$; Locomotion vs. Foraging: RRA: $P=0.59$, SH: $P=0.42, \mathrm{CHb}: P=0.11$, CHf: $P=0.79$ ).

Moreover, analysis of call proportions revealed distinct patterns for several call types. The proportions of RRA calls emitted after locomotion were significantly higher than after observing the surroundings, and the proportions of RRA calls emitted after these two behaviours were also significantly higher than after foraging (Binomial GLMM, Df $=2$, Chisq $=48440, p<0.0001$; 
least square means with Tukey correction for multiple comparisons: $\mathrm{L}$ vs. $\mathrm{O}$ : $\mathrm{z}=46.69$; $\mathrm{L}$ vs. F: $\mathrm{z}=-185.14 ; \mathrm{O}$ vs. $\mathrm{F}: \mathrm{z}=-119.02 ; \mathrm{p}<0.0001$ for the three tests).

Finally, distinct behavioural patterns were associated with contact call types (Fig. 5). Proportions of SH calls were significantly higher during foraging than during either observing the environment or locomotion (Binomial GLMM, Df $=2$, Chisq $=58.89, \mathrm{p}<0.0001$; least square mean with Tukey correction for multiple comparisons: $\mathrm{F}$ vs. $\mathrm{O}: \mathrm{z}=7.58, \mathrm{p}<0.0001$; $\mathrm{F}$ vs $\mathrm{L}: \mathrm{z}=$ 3.63, $P=0.0008$; O vs. $\mathrm{L}: \mathrm{z}=2.09, P=0.09)$. On the contrary, proportions of $\mathrm{CHb}$ calls were significantly lower after foraging than after observation or locomotion (Binomial GLMM, Df= 2, Chisq $=28.15, \mathrm{p}<0.0001$; least square mean with Tukey correction for multiple comparisons: F vs $\mathrm{O}: \mathrm{z}=-5.30, \mathrm{p}<0.0001 ; \mathrm{F}$ vs $\mathrm{L}: \mathrm{z}=-2.56, P=0.029 ; \mathrm{O}$ vs $\mathrm{L}: \mathrm{z}=-1.38, P=0.35)$. Proportions of CHf calls were significantly higher after observation than after foraging while the other comparisons did not reveal significant differences in the proportion of CHf calls (Binomial GLMM, $\mathrm{Df}=2$, Chisq $=6.14, P=0.046$; least square mean with Tukey correction for multiple comparisons: F vs $\mathrm{O}: \mathrm{z}=-2.47, P=0.036 ; \mathrm{F}$ vs $\mathrm{L}: \mathrm{z}=-1.75, P=0.19 ; \mathrm{O}$ vs $\mathrm{L}: \mathrm{z}=-0.21, P=0.98)$.

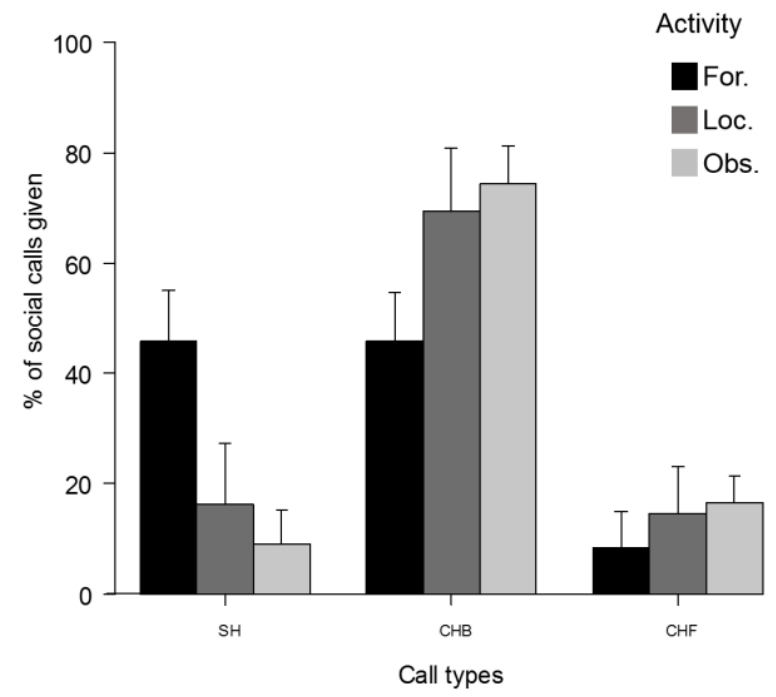

Figure 5: Mean proportion of total contact calls given represented by $\mathrm{SH}, \mathrm{CHb}$ and $\mathrm{CHf}$ calls immediately after foraging (black bars), locomotion (dark grey bars) and observation (light grey bars). Error bars show the standard error of the mean. See Table 1 and Methods (Variables and analyses section) for details.

\section{Vocal exchange}

Levels of vocal exchange varied with call type (Fig. 6). The rates of RRA were significantly higher for isolated than exchanged calls (Mann-Whitney, $N=10$, RRA: V= 45, $P=0.009$ ), but the rates for the three contact call types emitted alone or during exchanges did not differ significantly (Mann-Whitney, $N=10, \mathrm{SH}: \mathrm{V}=18, P=1$; CHb: $\mathrm{V}=11, P=0.19$; CHf: $\mathrm{V}=5, P=$ 0.08). 
Similarly, proportions of calls RRA calls uttered in isolation were significantly higher than exchanged (Binomial GLMM, Df= 1, Chisq= 43.04, p<0.0001, Fig. 6). Similar proportions of $\mathrm{SH}$ contact calls were uttered alone and during exchanges, but the proportions of $\mathrm{CHb}$ and $\mathrm{CHf}$ calls emitted during an exchange were significantly higher than the proportion of these calls given alone (Binomial GLMM, Df=1, $\mathrm{SH}$ : Chisq= 1.56, $P=0.21 ; \mathrm{CHb}$ : Chisq= 3.99, $P=0.046$; CHf: Chisq= 18.36, p<0.0001, Fig. 6).

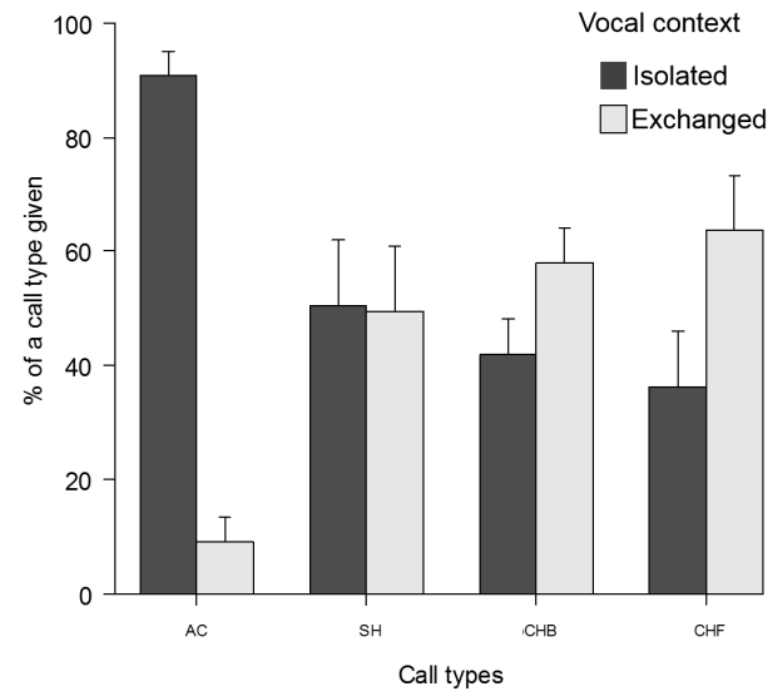

Figure 6: Average proportions of each call type emitted alone (dark bars) or during exchanges (light grey bars); Error bars show the standard error of the mean. See Table 1 and Methods (Variables and analyses section) for details.

Table 2: Main results concerning the immediate contextual factors. See Figure 1 for illustrations of 'arch addition' and 'arch completeness' on sonograms.

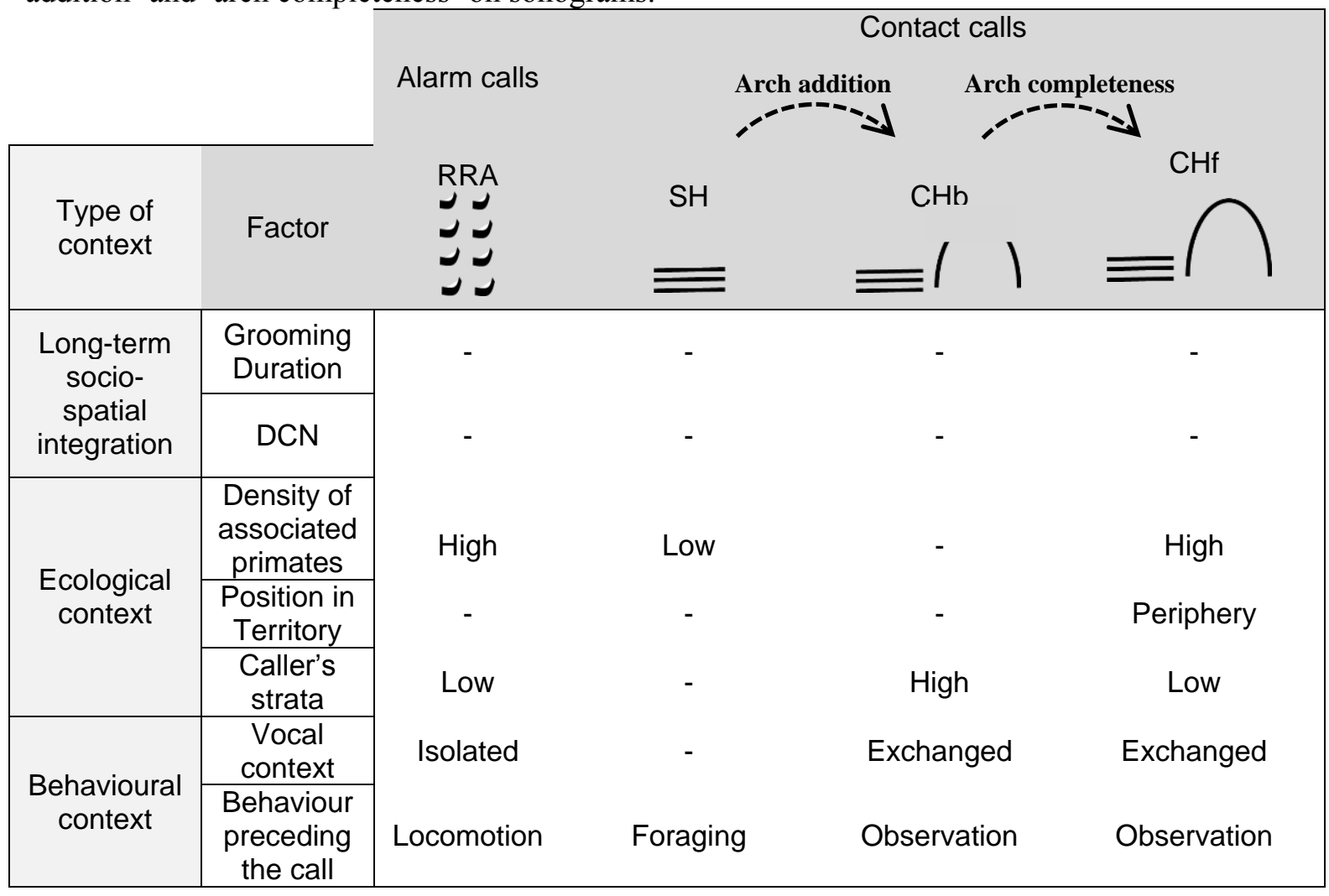




\section{DISCUSSION}

The aim of this study was to understand the socio-ecological factors influencing the use of the most common alarm and contact call types in female Campbell's monkeys. We found that a female's spatial and social integration in the group did not have any measurable effects on call use, for any call type tested. Call use, however, was significantly affected by the immediate context. Alarm calls were mainly used when the caller was in isolation or in a potentially 'risky' situation (Ouattara, Zuberbühler, N'goran, Gombert, \& Lemasson, 2009), such as when on the ground, when moving, or when the number of associated primate species was high (Buzzard, 2006; McGraw et al., 2007). Specifically, each of the three contact call types related to distinct contexts. SH calls were significantly associated with foraging behaviour, and their use increased when the density of associated primate species was low and the caller was on the ground (i.e. when danger was high). $\mathrm{CHb}$ and $\mathrm{CHf}$ calls were used preferentially during vocal exchanges and strongly associated with vigilance behaviour. $\mathrm{CHb}$ were the most frequent contact calls, but not significantly associated with specific situations. CHf calls, however, were associated strongly with contexts in which the need to signal identity was high (e.g. when the density of associated primates was high, when the group was at the periphery of its territory and when caller was on the ground).

\section{The evolution of combinatorial signalling}

The contact call system of female Campbell's monkeys is based on a simple combinatorial practice, the facultative addition of an arched unit (partial or full) to a low-pitched vocal unit. Our results firstly showed that call use by female Campbell's monkeys reflects the immediate context of calling. Therefore, females may use simple and combined calls flexibly depending on the immediate needs they face (e.g. to signal strongly one's identity or, on the contrary, to limit detection by predators). This is consistent with the theory that non-human primates have evolved combinatorial systems to defy their limited phonatory capacities (Arnold \& Zuberbühler, 2008; Zuberbühler \& Lemasson, 2014). Interestingly, this theory had been postulated based on studies describing combinations of alarm calls (Arnold, Pohlner, \& Zuberbühler, 2008; Clarke et al., 2006; Ouattara, Lemasson, et al., 2009b; Zuberbühler, 2000), supported by evidence sequence meaning deriving from call meaning (e.g. male Campbell's Hok-oo call ('non-urgent aerial threat'), consisting of Hok call ('urgent aerial threat') Hok call and oo 'suffix' that functions to signal decreased urgency). Our results are in line with this theory, and expand it to social communication. 
Our results strongly suggest that the need to signal identity flexibly depending on the context is likely to have influenced the evolution of contact calls in Campbell's monkeys. Call use by females is consistent with the increasing 'Potential for Identity Coding' described from SH to CHf calls (Lemasson \& Hausberger, 2011). Firstly, because CHf calls contain most identity information and are used preferentially when signalling identity is essential (e.g. during high densities of other primates around or when at the border of the territory). Identity-rich calls such as combined $\mathrm{CHb}$ and $\mathrm{CHf}$, but not $\mathrm{SH}$ calls, are used preferentially during vocal exchanges which function as indicators of social affinity (Lemasson, Gandon, et al., 2010; Lemasson \& Hausberger, 2004; Lemasson, Hausberger, \& Zuberbühler, 2005; Lemasson, Ouattara, Petit, \& Zuberbühler, 2011).

Recent studies also described combined contact calls in two other African primates. Interestingly, in these studies focussing respectively on red-capped mangabeys (Cercocebus torquatus) and Diana monkeys, the presence of combined vocalisations appeared to serve a social function (Bouchet, Pellier, Blois-Heulin, \& Lemasson, 2010b; Candiotti et al., 2012a). In red-capped mangabeys four distinct context-specific calls can be given alone or combined with an 'Uh' unit. The 'Uh' unit is never used alone but affixed to other calls, which seems to enhance vocal interactions (Bouchet et al., 2010). In Diana monkeys, a species closely related to Campbell's monkeys, females possess three distinct calls relating to the emotional state of the caller (i.e. H, L and R calls signalling respectively a positive, neutral and negative emotional state). Each of these can be given alone or combined with an arched call that signals caller's identity. While the presence and type of the introductory unit (H, L or R) depended on caller's emotional state, the addition of an arch and its type (i.e. full or broken, similar to female Campbell's monkeys' arched unit) depended on the need to signal caller's identity (Candiotti et al., 2012a).

Comparative research has suggested a relation between the complexity of call combination and social complexity (Bouchet et al., 2013; Manser et al., 2014). In African primates (Campbell's monkeys, red-capped mangabeys and De Brazza monkeys, Cercopithecus neglectus), the number of combined calls and their frequency of use is correlated with the species' social complexity index across species (Bouchet et al., 2013). In mongoose and meerkats (i.e. slender mongoose, Galerella sanguinea; yellow mongoose, Cynictis penicillata; dwarf mongoose, Helogale parvula; banded mongoose, Mungos mungo and meerkats Suricata suricatta) simple repetition of social and alarm calls are found in every species including solitary ones whereas the most complex combinations involving identity-rich signals are only found in the highly 
social banded mongooses (Jansen et al., 2012; Manser et al., 2014). In line with that, social combinations in meerkats are more varied in number of classes and structural complexity than alarm call combinations (Collier, Townsend \& Manser, 2017). Taken together, results suggest that the emergence and evolution of call combination is likely to result at least partly from increasingly complex social interactions which drive communicative complexity.

However, social needs alone are not sufficient to explain the vocal patterns observed. For instance, it does not explain why SH calls were maintained in their single form in the repertoire and were still used preferentially in some contexts, nor why $\mathrm{CHb}$ represented the vast majority of contact calls while CHf were more informative. One potential explanation has to do with predator-prey arms races. The maximum frequency of calls increase gradually from $\mathrm{SH}$, to $\mathrm{CHb}$ and to CHf (respectively about $850 \mathrm{~Hz}, 1900 \mathrm{~Hz}$ and $3500 \mathrm{~Hz}$ on average) and the same pattern is found for call intensity (Lemasson \& Hausberger, 2011). As a result CHf calls fall ideally into the hearing range of monkeys predators (i.e. crowned-hawk eagles, Stephanoaetus coronatus; leopards, Panthera pardus; and chimpanzees, Pan troglodytes) which all detect low frequency sounds (i.e. $<1 \mathrm{kHz}$ ) less well than higher frequency sounds around 4kHz (Heffner, 2004; Heffner \& Heffner, 1985; Huang, Rosowski, \& Peake, 2000; Yamazaki, Yamada, Murofushi, Momose, \& Okanoya, 2004). Acoustic avoidance (i.e. remaining silent to 'hide' from predators) and acoustic cryspis (i.e. using acoustic niches that are difficult for predators to detect) are common anti-predator responses in various species from marine mammals (Morisaka \& Connor, 2007) to birds (Klump, Kretzschmar, \& Curio, 1986) and insects (Ruxton, 2009).

Overall, our data are consistent with the notion of a trade-off between signalling identity, building social relations and maintain spatial cohesion on the one hand and avoiding detection by predators on the other hand. Diana monkeys are interesting in this light because they do not use crypsis as an anti-predator strategy (Candiotti et al., 2012a, 2012b; Uster \& Zuberbühler, 2001). It suggests that, while these two species evolved in the same polyspecific community of primates sharing territories to limit predation, the respective impact of social needs and predation risk have led to distinct communication strategies. This further highlights that some apparently small differences may have important implication for animals and that great attention to fine-tuned details must be paid. For instance, the preferential use of both SH and CHf calls by Campbell's monkeys when caller is on the ground remains intriguing and could reflect a dual pattern (e.g. using $\mathrm{SH}$ when arriving on the ground and $\mathrm{CHf}$ when leaving in order to find preferred partners, or using SH in visually open areas but CHf in closed ones). In addition to help clarify such questions, future studies comparing the vocal repertoire and calling behaviour 
of Campbell's and Diana monkeys would be helpful to get the full picture of their evolutionary path and to disentangle the relative balance of social life, predation and interspecific interactions in their communication.

More generally, this study suggests that several intricate factors influenced the emergence of combined calls in a forest-dwelling and highly social primate. The advantages of this vocal system together with the likely presence of combined vocalisations given in social contexts by phylogenetically distant primate species (i.e. Apes: gorillas, Gorilla spp., Hedwig, Hammerschmidt, Mundry, Robbins, \& Boesch, 2014; Hedwig et al., 2015; and chimpanzees Crockford \& Boesch, 2005; New world monkeys: cotton-top tamarins, Saguinus Oedipus, Cleveland \& Snowdon, 1982; wedged-capped capuchins, Cebus olivaceus, Robinson, 1984) and non-primates (e.g. banded mongooses, rock hyraxes, Procavia capensis Jansen et al., 2012; Kershenbaum et al., 2012; Manser et al., 2014) suggest that it may be an evolutionary solution more widespread than initially thought in species whose phonatory capacities may limit the complexification of communication. In addition, the presence of combined calls involving identity-related structures in several and phylogenetically distant highly social species (e.g. banded mongoose, Diana monkeys, Campbell's monkeys and red-capped mangabeys) supports the hypothesis that combination of vocal units is an evolutionary answer to the need for complex social communication in spite of limited capacities of vocal production. Interestingly however, these four distinct species also have limited visual access to others and face strong predatory constraints which role remains poorly understood. Future studies will be needed to further understand the relative impact of social needs, predation risk and other likely factors such as habitat's influence on visual access to others on the development of vocal combination in animals.

\section{ACKNOWLEDGEMENTS}

Research has been funded by the French Ministry of Research, the French University Institute (IUF), the National Agency for research (ANR 'Orilang') and the European Union's Seventh Framework Programme (FP7/2007-2013) / ERC grant agreement $\mathrm{n}^{\circ}$ 283871. The Ethics approval and permission to conduct research in Taï National Park were given by the Minister of Scientific Research and the 'Office Ivoirien des Parcs et Réserves' (OIPR). We thank A. Bitty, the Centre Suisse de Recherches Scientifiques and B. Diero for logistic support, as well as the Taï Chimpanzee Project (TCP) and the 'Centre de Recherche en Ecologie' (CRE) for their support in the field. We are very grateful to the Editor in charge of the review process of this manuscript and two anonymous reviewers for their helpful comments, and to Ann Cloarec for her help with language editing. All authors

contributed

equally

to

this

work. 


\section{REFERENCES}

Adret-Hausberger, M. (1982). Social influences on the whistled songs of starlings. Behavioral Ecology and Sociobiology, 11(4), 241-246. https://doi.org/10.1007/BF00299300

Adret-Hausberger, M. (1989). The speciesrepertoire of whistled songs in the European starling: species-specific characteristics and variability. Bioacoustics, 2(2), 137-162. https://doi.org/10.1080/09524622.19 89.9753123

Arlet, M., Jubin, R., Masataka, N., \& Lemasson, A. (2015). Grooming-ata-distance by exchanging calls in non-human primates. Biology Letters, 11(10), 20150711.

Arnold, K., \& Zuberbühler, K. (2008). Meaningful call combinations in a non-human primate. Current Biology, 18(5), R202-R203. https://doi.org/10.1016/j.cub.2008.0 1.040

Arnold, K., \& Zuberbühler, K. (2012). Call combinations in monkeys: Compositional or idiomatic expressions? Brain and Language, 120(3), 303-309. https://doi.org/10.1016/j.bandl.2011. 10.001

Bennett, A. T., \& Cuthill, I. C. (1994). Ultraviolet vision in birds: what is its function? Vision Research, 34(11), 1471-1478.

https://doi.org/10.1016/00426989(94)90149-X

Berwick, R. C., Okanoya, K., Beckers, G. J., \& Bolhuis, J. J. (2011). Songs to syntax: the linguistics of birdsong. Trends in Cognitive Sciences, 15(3), 113-121. https://doi.org/10.1016/j.tics.2011.01.002

Bohn, K. M., Schmidt-French, B., Ma, S. T., \& Pollak, G. D. (2008). Syllable acoustics, temporal patterns, and call composition vary with behavioral context in Mexican free-tailed bats. The Journal of the Acoustical Society of America, 124(3), 18381848. https://doi.org/10.1121/1.2953314

Bouchet, Helene, Blois-Heulin, C., \& Lemasson, A. (2013). Social complexity parallels vocal complexity: a comparison of three non-human primate species. Frontiers in Psychology, 4. https://doi.org/10.3389/fpsyg.2013.0 0390

Bouchet, Hélène, Blois-Heulin, C., Pellier, A.-S., Zuberbühler, K., \& Lemasson, A. (2012). Acoustic variability and individual distinctiveness in the vocal repertoire of red-capped mangabeys (Cercocebus torquatus). Journal of Comparative Psychology, 126(1), 45-56. https://doi.org/10.1037/a0025018

Bouchet, Hélène, Pellier, A.-S., BloisHeulin, C., \& Lemasson, A. (2010a). Sex differences in the vocal repertoire of adult red-capped mangabeys (Cercocebus torquatus): a multi-level acoustic analysis. American Journal of Primatology, 72(4), 360-375. https://doi.org/10.1002/ajp.20791

Bouchet, Hélène, Pellier, A.-S., BloisHeulin, C., \& Lemasson, A. (2010b). Sex differences in the vocal repertoire of adult red-capped mangabeys (Cercocebus torquatus): a multi-level acoustic analysis. American Journal of Primatology, 
72(4),

$360-375$.

https://doi.org/10.1002/ajp.20791

Brown, C. H., Gomez, R., \& Waser, P. M. (1995). Old world monkey vocalizations: adaptation to the local habitat? Animal Behaviour, 50(4), 945-961.

https://doi.org/10.1016/0003-

3472(95)80096-4

Buzzard, P., \& Eckardt, W. (2007). The social system of guenons. In S. W. McGraw, K. Zuberbühler, \& R. Noë (Eds.), Monkeys of the Tai Forest: An African Primate Community (pp. 51-71). Cambridge University Press.

Buzzard, P. J. (2006). Cheek pouch use in relation to interspecific competition and predator risk for three guenon monkeys (Cercopithecus spp.). Primates, 47(4), 336-341. https://doi.org/10.1007/s10329-0060188-6

Candiotti, A., Coye, C., Ouattara, K., Petit, E. J., Vallet, D., Zuberbühler, K., \& Lemasson, A. (2015). Female Bonds and Kinship in Forest Guenons. International Journal of Primatology, 1-21. https://doi.org/10.1007/s10764-0159829-1

Candiotti, A., Zuberbühler, K., \& Lemasson, A. (2012a). Contextrelated call combinations in female Diana monkeys. Animal Cognition, 15(3), 327-339. https://doi.org/10.1007/s10071-0110456-8

Candiotti, A., Zuberbühler, K., \& Lemasson, A. (2012b). Convergence and divergence in Diana monkey vocalizations. Biology Letters, 8(3), 382-385.

https://doi.org/10.1098/rsbl.2011.11 82
Candiotti, A., Zuberbühler, K., \& Lemasson, A. (2013). Voice discrimination in four primates. Behavioural Processes, 99, 67-72. https://doi.org/10.1016/j.beproc.201 3.06 .010

Cäsar, C., Byrne, R., Young, R. J., \& Zuberbühler, K. (2012, May 1). The alarm call system of wild blackfronted titi monkeys, Callicebus nigrifrons. Behavioral Ecology and Sociobiology, pp. 653-667. DOI: 10.1007/s00265-011-1313-0

Clarke, E., Reichard, U. H., \& Zuberbühler, K. (2006). The Syntax and Meaning of Wild Gibbon Songs. PLoS ONE, 1(1), e73. https://doi.org/10.1371/journal.pone. 0000073

Clay, Z., \& Zuberbühler, K. (2011). Bonobos Extract Meaning from Call Sequences. PLoS ONE, 6(4), e18786.

https://doi.org/10.1371/journal.pone. 0018786

Cleveland, J., \& Snowdon, C. T. (1982). The complex vocal repertoire of the adult cotton-top tamarin (Saguinus oedipus oedipus). Ethology, 58(3), 231-270.

https://doi.org/10.1111/j.14390310.1982.tb00320.x

Collier, K., Bickel, B., Schaik, C. P. van, Manser, M. B., \& Townsend, S. W. (2014). Language evolution: syntax before phonology? Proceedings of the Royal Society B: Biological Sciences, 281(1788), 20140263. https://doi.org/10.1098/rspb.2014.02 63

Coye, C., Ouattara, K., Zuberbühler, K., \& Lemasson, A. (2015). Suffixation influences receivers' behaviour in non-human primates. Proceedings of 
the Royal Society of London B:

Biological Sciences, 282(1807), 20150265.

https://doi.org/10.1098/rspb.2015.02 65

Coye, C., Zuberbühler, K., \& Lemasson, A. (2016). Morphologically structured vocalizations in female Diana monkeys. Animal Behaviour, 115, 97-105.

https://doi.org/10.1016/j.anbehav.20 16.03.010

Crockford, C., \& Boesch, C. (2005). Call combinations in wild chimpanzees. Behaviour, 142(4), 397-421. https://doi.org/10.1163/1568539054 012047

Engesser, S., Crane, J. M., Savage, J. L., Russell, A. F., \& Townsend, S. W. (2015). Experimental evidence for phonemic contrasts in a nonhuman vocal system. PLoS Biology, 13(6), e1002171.

https://doi.org/10.1371/journal.pbio. 1002171

Engesser, S., Ridley, A. R., \& Townsend, S.

W. (2016). Meaningful call combinations and compositional processing in the southern pied babbler. Proceedings of the National Academy of Sciences, 113(21), 5976-5981.

https://doi.org/10.1073/pnas.160097 0113

Freeberg, T. M., Dunbar, R. I. M., \& Ord, T. J. (2012). Social complexity as a proximate and ultimate factor in communicative complexity. Philosophical Transactions of the Royal Society of London B: Biological Sciences, 367(1597), 1785-1801.

https://doi.org/10.1098/rstb.2011.02 13
Furrer, R. D., \& Manser, M. B. (2009). The evolution of urgency-based and functionally referential alarm calls in ground-dwelling species. The American Naturalist, 173(3), 400410. https://doi.org/10.1086/596541

Gautier, J.P., Gautier-Hion A. (1977). Communication in Old World Monkeys. How Animals Communicate, (Indiana University Press, pp.890-964). Eds: Thomas Albert Sebeok. https://hal-univrennes1.archives-ouvertes.fr/hal01371645

Gustison, M. L., Roux, A. le, \& Bergman, T. J. (2012). Derived vocalizations of geladas (Theropithecus gelada) and the evolution of vocal complexity in primates. Philosophical Transactions of the Royal Society of London B: Biological Sciences, 367(1597), 1847-1859. https://doi.org/10.1098/rstb.2011.02 18

Hammerschmidt, K., \& Fischer, J. (2008). Constraints in primate vocal production. In Evolution of communicative flexibility: complexity, creativity, and adaptability in human and animal communication (The MIT Press, Cambridge, pp. 93-119). Oller D.K. \& Griebel U.

Hauser, M. D. (1996). The Evolution of Communication. Cambridge, MA, US: The MIT Press.

Hedwig, D., Hammerschmidt, K., Mundry, R., Robbins, M. M., \& Boesch, C. (2014). Acoustic structure and variation in mountain and western gorilla close calls: a syntactic approach. Behaviour, 151(8), 1091- 
1120. DOI: $10.1163 / 1568539 X-$ 00003175

Hedwig, D., Mundry, R., Robbins, M. M., \& Boesch, C. (2015). Contextual correlates of syntactic variation in mountain and western gorilla closedistance vocalizations: Indications for lexical or phonological syntax? Animal Cognition, 18(2), 423-435. https://doi.org/10.1007/s10071-0140812-6

Heffner, R. S. (2004). Primate hearing from a mammalian perspective. The Anatomical Record, 281(1), 11111122.

https://doi.org/10.1002/ar.a.20117

Heffner, R. S., \& Heffner, H. E. (1985). Hearing range of the domestic cat. Hearing Research, 19(1), 85-88. https://doi.org/10.1016/03785955(85)90100-5

Henry, L., \& Hausberger, M. (2001). Differences in the social context of song production in captive male and female European starlings. Comptes Rendus de l'Académie Des SciencesSeries III-Sciences de La Vie, 324(12), 1167-1174. https://doi.org/10.1016/S07644469(01)01394-4

Huang, G., Rosowski, J., \& Peake, W. (2000). Relating middle-ear acoustic performance to body size in the cat family: measurements and models. Journal of Comparative Physiology A, 186(5), 447-465. https://doi.org/10.1007/s0035900504 44

Jansen, D. A., Cant, M. A., \& Manser, M. B. (2012). Segmental concatenation of individual signatures and context cues in banded mongoose (Mungos mungo) close calls. BMC Biology, 10(1),

97. https://doi.org/10.1186/1741-700710-97

Keenan, S., Lemasson, A., \& Zuberbühler, K. (2013). Graded or discrete? A quantitative analysis of Campbell's monkey alarm calls. Animal Behaviour, 85(1), 109-118. https://doi.org/10.1016/j.anbehav.20 12.10.014

Kershenbaum, A., Ilany, A., Blaustein, L., \& Geffen, E. (2012). Syntactic structure and geographical dialects in the songs of male rock hyraxes. Proceedings of the Royal Society of London B: Biological Sciences, 279(1740), 2974-2981.DOI: 10.1098/rspb.2012.0322

Klump, G., Kretzschmar, E., \& Curio, E. (1986). The hearing of an avian predator and its avian prey. Behavioral Ecology and Sociobiology, 18(5), 317-323. https://doi.org/10.1007/BF00299662

Knotkova, E., Veitl, S., Sumbera, R., Sedlacek, F., \& Burda, H. (2009). Vocalisations of the silvery mole-rat: comparison of vocal repertoires in subterranean rodents with different social systems. Bioacoustics, 18(3), 241-257.

https://doi.org/10.1080/09524622.20 09.9753604

Kondo, N., \& Watanabe, S. (2009). Contact calls: information and social function. Japanese Psychological Research, 51(3), 197-208. https://doi.org/10.1111/j.14685884.2009.00399.x

Lameira, A. R., Maddieson, I., \& Zuberbühler, K. (2014). Primate feedstock for the evolution of consonants. Trends in Cognitive Sciences, $\quad$ 18(2), 60-62. 
https://doi.org/10.1016/j.tics.2013.10 .013

Le Roux, A., Cherry, M. I., \& Manser, M. B. (2009). The vocal repertoire in a solitary foraging carnivore, Cynictis penicillata, may reflect facultative sociality. Naturwissenschaften, 96(5), 575-584. https://doi.org/10.1007/s00114-0080506-5

Lehmann, J., Korstjens, A. H., \& Dunbar, R. I. M. (2007). Group size, grooming and social cohesion in primates. Animal Behaviour, 74(6), 16171629.

https://doi.org/10.1016/j.anbehav.20 06.10 .025

Leliveld, L. M., Scheumann, M., \& Zimmermann, E. (2011). Acoustic correlates of individuality in the vocal repertoire of a nocturnal primate (Microcebus murinus). The Journal of the Acoustical Society of America, 129(4), 2278-2288. https://doi.org/10.1121/1.3559680

Lemasson, A., \& Hausberger, M. (2011). Acoustic variability and social significance of calls in female Campbell's monkeys (Cercopithecus campbelli campbelli). The Journal of the Acoustical Society of America, 129(5),

3341-3352. https://doi.org/10.1121/1.3569704

Lemasson, Alban, Gandon, E., \& Hausberger, M. (2010). Attention to elders' voice in non-human primates. Biology Letters, 6(3), 325$328 . \quad$ https://doi.org/DOI: 10.1098/rsbl.2009.0875

Lemasson, Alban, \& Hausberger, M. (2004). Patterns of Vocal Sharing and Social Dynamics in a Captive Group of Campbell's Monkeys (Cercopithecus campbelli campbelli). Journal of Comparative Psychology, 118(3), 347-359. https://doi.org/10.1037/0735-

7036.118.3.347

Lemasson, Alban, Hausberger, M., \& Zuberbühler, K. (2005). Socially Meaningful Vocal Plasticity in Adult Campbell's Monkeys (Cercopithecus campbelli). Journal of Comparative Psychology, 119(2), 220-229.

https://doi.org/10.1037/0735-

7036.119.2.220

Lemasson, Alban, Ouattara, K., Bouchet, H., \& Zuberbühler, K. (2010). Speed of call delivery is related to context and caller identity in Campbell's monkey males. Naturwissenschaften, 97(11), 1023-1027. https://doi.org/10.1007/s00114-0100715-6

Lemasson, Alban, Ouattara, K., Petit, E. J., \& Zuberbühler, K. (2011). Social learning of vocal structure in a nonhuman primate? BMC Evolutionary Biology, 11(1), 362. https://doi.org/10.1186/1471-214811-362

Liebal, K., Waller, B. M., Slocombe, K. E., \& Burrows, A. M. (2013). Primate Communication: a multimodal approach. Cambridge University Press.

Manser, M. B. (2001). The acoustic structure of suricates' alarm calls varies with predator type and the level of response urgency. Proceedings of the Royal Society of London. Series B: Biological Sciences, 268(1483), 2315-2324. https://doi.org/10.1098/rspb.2001.17 73

Manser, M. B., Jansen, D. A., Graw, B., Hollén, L. I., Bousquet, C. A., 
Furrer, R. D., \& le Roux, A. (2014). Vocal complexity in meerkats and other mongoose species. Advances in the Study of Behavior, 46, 281.

Marler, P. (1965). Communication in monkeys and apes. Primate Behaviour, pp. 544-584.

McComb, K., \& Semple, S. (2005). Coevolution of vocal communication and sociality in primates. Biology Letters, 1(4), 381385.

https://doi.org/10.1098/rsbl.2005.03 66

Mcgraw, W. S., \& Zuberbühler, K. (2008). Socioecology, predation, and cognition in a community of West African monkeys. Evolutionary Anthropology: Issues, News, and Reviews, 17(6), 254-266. https://doi.org/10.1002/evan.20179

McGraw, W. S., Zuberbühler, K., \& Noë, R. (2007). Monkeys of the Tai Forest: An African Primate Community. Cambridge University Press.

Morisaka, T., \& Connor, R. (2007). Predation by killer whales (Orcinus orca) and the evolution of whistle loss and narrow-band high frequency clicks in odontocetes. Journal of Evolutionary Biology, 20(4), 14391458. https://doi.org/10.1111/j.14209101.2007.01336.x

Oda, R. (1996). Effects of contextual and social variables on contact call production in free-ranging ringtailed lemurs (Lemur catta). International Journal of Primatology, 17(2), 191205. Retrieved from http://cat.inist.fr/?aModele=afficheN \&cpsidt $=3052754$

Osorio, D., \& Vorobyev, M. (2008). A review of the evolution of animal colour vision and visual communication signals. Vision Research, 48(20), 2042-2051. https://doi.org/10.1016/j.visres.2008. 06.018

Ouattara, K., Lemasson, A., \& Zuberbühler, K. (2009a). Campbell's monkeys concatenate vocalizations into context-specific call sequences. Proceedings of the National Academy of Sciences, 106(51), 22026-22031. https://doi.org/10.1073/pnas.090811 8106

Ouattara, K., Lemasson, A., \& Zuberbühler, K. (2009b). Campbell's Monkeys Use Affixation to Alter Call Meaning. PLoS ONE, 4(11), e7808. https://doi.org/10.1371/journal.pone. 0007808

Ouattara, K., Zuberbühler, K., N'goran, E. K., Gombert, J.-E., \& Lemasson, A. (2009). The alarm call system of female Campbell's monkeys. Animal Behaviour, 78(1), 35-44. https://doi.org/10.1016/j.anbehav.20 09.03.014

Palombit, R. A., Seyfarth, R. M., \& Cheney, D. L. (1997). The adaptive value of 'friendships' to female baboons: experimental and observational evidence. Animal Behaviour, 54(3), 599-614.

https://doi.org/10.1006/anbe.1996.04 57

Pereira, M. E., \& Macedonia, J. M. (1991). Ringtailed lemur anti-predator calls denote predator class, not response urgency. Animal Behaviour, 41(3), 543-544.

https://doi.org/10.1016/S00033472(05)80861-9

Pollard, K. A., \& Blumstein, D. T. (2012). Evolving communicative complexity: insights from rodents 
and beyond. Phil. Trans. R. Soc. B, 367(1597), 1869-1878. DOI: 10.1098/rstb.2011.0221

Rendall, D., Rodman, P. S., \& Emond, R. E. (1996). Vocal recognition of individuals and kin in free-ranging rhesus monkeys. Animal Behaviour, 51(5), 1007-1015. https://doi.org/10.1006/anbe.1996.01 03

Richard, J.-P. (1991). Sound analysis and synthesis using an Amiga microcomputer. Bioacoustics, 3(1), 45-60. https://doi.org/10.1080/09524622.19 91.9753156

Robinson, J. G. (1984). Syntactic structures in the vocalizations of wedge-capped capuchin monkeys, Cebus olivaceus. Behaviour, 90(1), 46-78. https://doi.org/10.1163/156853984X 00551

Ruxton, G. D. (2009). Non-visual crypsis: a review of the empirical evidence for camouflage to senses other than vision. Philosophical Transactions of the Royal Society B: Biological Sciences, 364(1516), 549-557. https://doi.org/10.1098/rstb.2008.02 28

Seyfarth, R. M., Cheney, D. L., \& Bergman, T. J. (2005). Primate social cognition and the origins of language. Trends in Cognitive Sciences, 9(6), 264266.

https://doi.org/10.1016/j.tics.2005.04 .001

Smith, W. J. (1965). Message, meaning, and context in ethology. The American Naturalist, 99(908), 405-409. https://doi.org/10.1086/282382

Stephan, C., \& Zuberbühler, K. (2008). Predation increases acoustic complexity in primate alarm calls. Biology Letters, 4(6), 641-644. https://doi.org/10.1098/rsbl.2008.04 88

Suzuki, T. N., Wheatcroft, D., \& Griesser, M. (2016). Experimental evidence for compositional syntax in bird calls. Nature Communications, 7, 10986

https://doi.org/10.1038/ncomms1098 6

ten Cate, C., \& Okanoya, K. (2012). Revisiting the syntactic abilities of non-human animals: natural vocalizations and artificial grammar learning. Philosophical Transactions of the Royal Society B: Biological Sciences, 367(1598), 1984-1994. https://doi.org/10.1098/rstb.2012.00 55

Uster, D., \& Zuberbühler, K. (2001). The functional significance of Diana monkey clear' calls. Behaviour, 138, 741-756.

https://doi.org/10.1163/1568539017 52233389

Vignal, C., Mathevon, N., \& Mottin, S. (2004). Audience drives male songbird response to partner's voice. Nature, $\quad 430(6998), \quad 448$. https://doi.org/10.1038/nature02645

Waser, P. M., \& Brown, C. H. (1986). Habitat acoustics and primate communication. American Journal of Primatology, 10(2), 135-154. https://doi.org/10.1002/ajp.1350100 205

Wyatt, T. D. (2003). Pheromones and animal behaviour: communication by smell and taste. Cambridge, UK: Cambridge university press.

Yamazaki, Y., Yamada, H., Murofushi, M., Momose, H., \& Okanoya, K. (2004). Estimation of hearing range in raptors using unconditioned responses. Ornithological Science, 
$3(1)$,

85-92.

https://doi.org/10.2326/osj.3.85

Zuberbühler, K. (2002). A syntactic rule in forest monkey communication. Animal Behaviour, 63(2), 293-299. https://doi.org/10.1006/anbe.2001.19 14

Zuberbühler, K., \& Lemasson, A. (2014). Primate Communication: Meaning from Strings of Calls. In F. Lowenthal \& L. Lefebvre (Eds.), Language and Recursion (pp. 115125). Springer New York. Retrieved from

http://link.springer.com/chapter/10.1 007/978-1-4614-9414-0_9 


\section{APPENDIX:}

Table A1: Definition of the contextual variables used for the study. DCN stands for 'Distance to the Closest Neighbour'.

\begin{tabular}{|c|c|c|c|c|}
\hline Context & Variable & $\begin{array}{l}\text { Sampling } \\
\text { method }\end{array}$ & Categories & Description \\
\hline \multirow{3}{*}{$\begin{array}{l}\text { Long-term } \\
\text { socio-spatial } \\
\text { integration in } \\
\text { the group }\end{array}$} & \multirow[b]{2}{*}{ Grooming } & \multirow[b]{2}{*}{ Focal } & With male & Time spent grooming/being groomed by the adult male, per minute of observation \\
\hline & & & With female & Time spent grooming/being groomed by an adult female, per minute of observation \\
\hline & DCN & Scan & Distance $(\mathrm{m})$ & Distance to the closest conspecific $(\mathrm{m})$ \\
\hline \multirow{5}{*}{$\begin{array}{c}\text { Immediate } \\
\text { environmental } \\
\text { context }\end{array}$} & \multirow{2}{*}{$\begin{array}{l}\text { Number of } \\
\text { associated } \\
\text { primate } \\
\text { species }\end{array}$} & \multirow{2}{*}{ Scan } & Low density & $\begin{array}{l}\text { No or only one other primate group within } 50 \mathrm{~m} \text {. When another primate species was present, it was } \\
\text { always a cryptic species, in a smaller group (C. verus) or with smaller individuals (C. petaurista) }\end{array}$ \\
\hline & & & High density & Two associated species or more under $50 \mathrm{~m}$ from the group \\
\hline & Position in & \multirow{2}{*}{ Scan } & Centre & More than $100 \mathrm{~m}$ from the border of the territory (Ouattara, Lemasson, et al., 2009a) \\
\hline & the territory & & Periphery & Under $100 \mathrm{~m}$ from the border of the territory (Ouattara, Lemasson, et al., 2009a) \\
\hline & $\begin{array}{l}\text { Stratum } \\
\text { used } \\
\text { (McGraw, } \\
\text { 1998) }\end{array}$ & Focal & $\begin{array}{l}\text { Strata } 0 \\
\text { Strata } 1 \\
\text { Strata } 2 \\
\text { Strata } 3\end{array}$ & $\begin{array}{c}\text { On the ground } \\
0-5 \text { meters from the ground } \\
5-20 \mathrm{~m} \text { high } \\
20-40 \mathrm{~m} \text { high }\end{array}$ \\
\hline \multirow{3}{*}{$\begin{array}{l}\text { Immediate } \\
\text { behavioural } \\
\text { context }\end{array}$} & $\begin{array}{l}\text { Behaviour } \\
\text { preceding } \\
\text { the call }\end{array}$ & Focal & $\begin{array}{l}\text { Important } \\
\text { locomotion } \\
\text { Feeding } \\
\text { Observation }\end{array}$ & $\begin{array}{l}\text { Potentially stressful locomotor activity: Going to the ground, climbing up or down (strata changes), } \\
\text { jumping } \\
\text { Eat: The animal puts a food item in the mouth } \\
\text { Observation of the environment: Scanning the ground, looking above and under, scanning the } \\
\text { environment in vigilance posture }\end{array}$ \\
\hline & Vocal & & Exchanged & Call given within $1 \mathrm{~s}$ from a call of a conspecific \\
\hline & $\begin{array}{l}\text { context: } \\
\text { isolated vs } \\
\text { exchanged }\end{array}$ & Focal & Isolated & Call given more than $1 \mathrm{~s}$ away from a call of a conspecific \\
\hline
\end{tabular}

